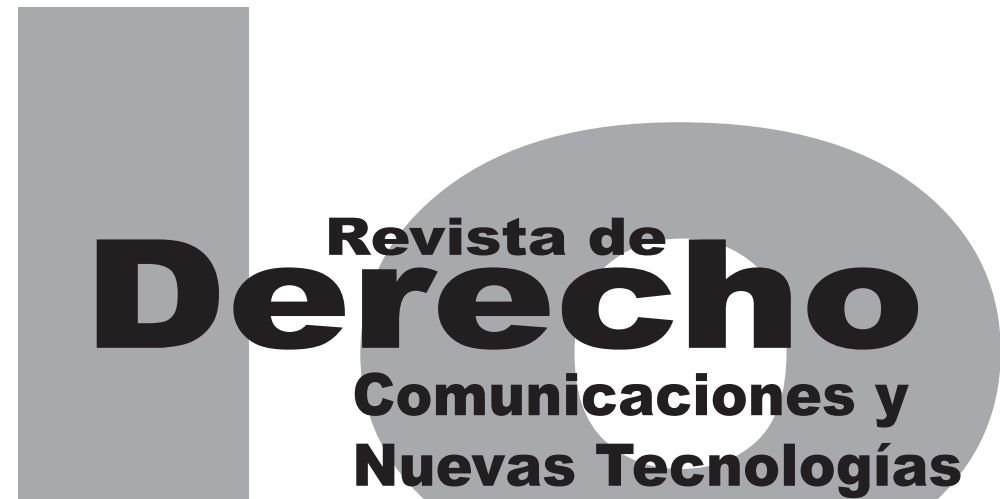

\title{
SATÉLITES ESPÍA: ¿FUENTE DE DESCONFIANZA O DE SEGURIDAD?
}

\author{
JULIANA VARGAS \\ MARgARITA FANDIÑo \\ Artículo de reflexión \\ DOI: http://dx.doi.org/10.15425/redecom.12.2014.16
}

\author{
Universidad de los Andes \\ Facultad de Derecho
}

Revista de Derecho, Comunicaciones y Nuevas Tecnologías

No. 12, Julio - Diciembre de 2014. ISSN 1909-7786 


\section{Satélites espía: ¿fuente de desconfianza o de seguridad?}

\section{Resumen}

Durante la carrera espacial (1957-1975) la Comunidad Internacional observó con preocupación el clima de desconfianza entre Estados Unidos y Rusia que desencadenó en actos de espionaje que involucraron al espacio ultraterrestre. El siguiente texto describe el marco normativo que regula la utilización de satélites espía en el espacio, así como sus aspectos técnicos. La investigación evidencia que la utilización está prohibida en tiempos de paz y solo hay una excepción que es la legítima defensa. Sin embargo, el uso de satélites espía es común y nunca es notificado; por tanto, es necesario que los satélites sean utilizados bajo un plan de cooperación internacional que, en lugar de fomentar la desconfianza, fomente seguridad global.

Palabras clave: espacio ultraterrestre, Tratado de 1967, teleobservación, satélites de teleobservación, espionaje, satélites espía, satélites militares, legalidad de los satélites espía, uso de los satélites espía.

\section{Spy satellites : source of mistrust or security?}

\section{Abstract}

During the Space Race (1957-1975) the international community was concerned the climate of mistrust between the U.S. and Russia, who unleashed in espionage involving outer space. The following describes the regulatory framework governing the use of spy satellites in space, as well as technical aspects thereof. Research shows that the use is prohibited in peacetime and there is only one exception that is self-defense. However, the use of spy satellites is common and almost never reported, so satellites must be used for encouraging global security instead of encouraging mistrust.

Keywords: Outer Space Treaty of 1967, spy, spy satellites, military satellites, legality of spy satellites, use of spy satellites, earth observation satellites.

\section{Satélites espiões: fonte de desconfiança ou de segurança?}

\section{Resumo}

Durante a corrida espacial (1957-1975), a comunidade internacional observou com preocupação o clima de desconfiança entre os Estados Unidos e a Rússia que desencadeou em atos de espionagem que envolveram o espaço ultraterrestre. 0 seguinte texto descreve o marco normativo que regula a utilização de satélites espiões no espaço, assim como aspectos técnicos dos mesmos. A investigação evidencia que sua utilização está proibida em tempos de paz e só há uma exceção que é a legítima defesa. Porém, o uso de satélites espiões é comum e nunca é notificado; portanto, é necessário que os satélites sejam utilizados sob um plano de cooperação internacional que, em lugar de fomentar a desconfiança, fomente segurança global.

Palavras-chave: espaço ultraterrestre, Tratado de 1967, tele observação, satélites de tele observação, espionagem, satélites espiões, satélites militares, legalidade dos satélites espiões, uso dos satélites espiões. 


\title{
Satélites espía: ¿fuente de desconfianza o de seguridad?*
}

\author{
Juliana Vargas** \\ Margarita Fandiño***
}

\section{SUMARIO}

Introducción. A. Contexto histórico. B. Pregunta de investigación. I. ASPECTOS TÉCNICOS DE LOS SATÉLITES ESPÍA. A. Características y definición de los satélites espía. 1. Qué es el espionaje. 2. A qué género pertenecen los satélites espía. 3. Cómo funcionan los satélites espía. 4. Qué tan nítida puede ser la imagen de un satélite espía. 5. Clasificación de los satélites espía. 5.1. Satélites de formación de imágenes. 5.2. Satélites de reconocimiento electrónico. 5.3. Satélites de vigilancia del océano. 5.4. Los satélites militares para usos meteorológicos. II. ASPECTOS JURÍDICOS DE LOS SATÉLITES ESPÍA. A. Espionaje en el derecho internacional. B. Regularización de la militarización del espacio ultraterrestre. C. Legalidad del uso de los satélites espía. III. REALIDAD SOBRE EL USO DE LOS SATÉLITES ESPÍA. IV. LA CORRECTA UTILIZACIÓN DE LOS SATÉLITES ESPÍA: DE VISIÓN LOCAL A VISIÓN GLOBAL DE LA SEGURIDAD. V. CONCLUSIONES. Bibliografía.

* Cómo citar este artículo: Vargas, J. y Fandiño, M. (Diciembre, 2014). Satélites espía: ¿Fuente de desconfianza o de seguridad? Revista de Derecho, Comunicaciones y Nuevas Tecnologías, 12. Universidad de los Andes (Colombia).

** Estudiante de pregrado de la Facultad de Derecho y opción en Literatura y Periodismo de la Universidad de los Andes. Actualmente cursa noveno semestre. Correo electrónico:j.vargas975@uniandes.edu.co.

*** Estudiante de pregrado de las facultades de Derecho y Filosofía de la Universidad de los Andes. Actualmente cursa decimo semestre de Derecho y quinto de Filosofía. Correo electrónico: mm.fandino611@uniandes.edu.co. 
introducción

\section{A. Contexto histórico}

Era 1945, un año que vería el fin de la Segunda Guerra Mundial. Francia, Gran Bretaña, la Unión Soviética y Estados Unidos estaban aliados en contra de Alemania, Italia y Japón. Como desafortunadamente acontece con toda guerra, la pérdida de vidas civiles es inevitable. El 6 de agosto de 1945 lo último que vieron aproximadamente 70000 ciudadanos de Hiroshima fue una explosión de 50 kilos de uranio-235 liberando por fisión una energía equivalente a 15000 toneladas de dinamita. Al caer sobre la ciudad, la bomba Ilamada "Little Boy", creada por los estadounidenses, la cual originó una bola de fuego de 256 metros de diámetro elevando la temperatura a un millón de grados centígrados. El 9 de agosto la bomba "Fat Man" cayó sobre Nagasaki. Esta bomba tenía una fuerza equivalente al doble de Little Boy, causando que más de 80000 personas murieran (Centro de Estudios Humanistas, 2013).

El mundo no ha visto un acto tan desastroso como este. La gran impresión que causó la fuerza de la energía nuclear hizo que Japón se rindiera ante los Aliados el 15 de agosto de ese mismo año y, además, que se terminara la guerra. El fin de la guerra significó una reestructuración del poder. En la Conferencia de Postdam, los Aliados se reunieron para disponer las normas a seguir para gestionar a la derrotada Alemania. Con ellos el territorio alemán fue dividido en cuatro, un territorio por cada Estado ga- nador. Poco después, Estados Unidos, Francia y Gran Bretaña fusionaron sus territorios en la República Federal de Alemania (RFA o Alemania Occidental). La Unión Soviética reaccionó creando en 1949 la República Democrática Alemana (RDA o Alemania Oriental) (Cide, 2014).

Esta división creó la Guerra Fría pues el mundo había quedado claramente dividido en dos bloques: el bloque occidental, liderado por la superpotencia estadounidense, y el bloque oriental, liderado por la superpotencia soviética. Así, comenzó un enfrentamiento ideológico entre la visión capitalista estadounidense y la comunista soviética. En suma, se dio “[...] un estado de tensión permanente, primero entre las dos superpotencias (Estados Unidos y la Unión Soviética) y luego entre los dos bloques liderados por ellas, que no provocó un conflicto directo ante el peligro de destrucción mutua y asegurada por la utilización de las armas nucleares" (Pereira, 1997, p. 11).

Uno de los escenarios de enfrentamiento entre las dos superpotencias fue el espacio. Para la época, lo que se encontraba más allá de la atmósfera terrestre era un misterio y llegar hasta ella parecía ser un acto simbólico de poderío, puesto

que, quien llegara al espacio, podría abarcar el mundo entero con tan solo una mirada. Quien llegara al espacio entonces dominaría el mundo. Por esa razón, la carrera espacial fue una de las expresiones de la confrontación entre Estados Unidos y la Unión Soviética. 
La primera potencia en asestar un golpe fue la Unión Soviética con el lanzamiento del satélite artificial Sputnik I, el 4 de octubre de 1957. Estados Unidos aún no despertaba de su estupor cuando el 3 de noviembre del mismo año fue lanzado el Sputnik II, esta vez con un ser vivo abordo: una perra llamada Laika. Posteriormente, el cosmonauta Yuri Gagarin fue la primera persona en disfrutar la vista de la Tierra desde el espacio, el 12 de abril de 1961 (Risi, 2014).

Entretanto, Estados Unidos buscaba la forma de alcanzar a su rival. "En 1961, el presidente John F. Kennedy anunciaba un plan que, indirectamente, consolidaba la carrera espacial como una pulseada entre dogmas políticos. Era el nacimiento del programa Apollo" (Risi, 2014). Así, el 20 de julio de 1969, logró su cometido. Ese día, casi una década después de que el Sputnik I emitiera a todo el planeta un intermitente y repetitivo beep-beep en nombre del comunismo, el astronauta Neil Armstrong fue el primer hombre en pisar la Luna.

La comunidad internacional observaba con preocupación estos eventos. Las preguntas que se hacían eran: ¿Ahora el espacio podrá convertirse en un escenario bélico?, ¿puede ser un lugar objeto de apropiación y soberanía?, ¿cuál es el límite? Con el fantasma de las bombas atómicas utilizadas en la Segunda Guerra Mundial, extender un escenario bélico al espacio ultraterrestre posibilitaba un enfrentamiento entre las dos potencias con daños mundiales ¿Cómo hacer para evitar una guerra que podría alcanzar niveles de afectación inimaginables? Mientras ocurrían los acontecimientos anteriormente mencionados, la respuesta se dio en el marco de las Naciones Unidas, que "estableció para esa tarea un órgano especial, la Comisión sobre la Utilización del Espacio Ultraterrestre con Fines Pacíficos, al inicio como comisión ad hoc en 1958 y desde 1959 como órgano permanente. (Kopal, 2009, p. 1).

La Declaración de los principios jurídicos que deben regir las actividades de los Estados en la exploración y utilización del espacio ultraterrestre, aprobada por consenso por la Asamblea General en su Resolución 1962, del 13 de diciembre de 1963, fue el primer avance para regular la actividad espacial. Sin embargo, si se quería eliminar cualquier posibilidad de guerras con alcances magnánimos era necesario un instrumento con la suficiente vinculatoriedad para obligar a los Estados a siquiera pensar en la posibilidad. Dicho instrumento se creó en 1967 con el Tratado sobre los principios que deben regir las actividades de los Estados en la exploración y utilización del espacio ultraterrestre, incluso la Luna y otros cuerpos celestes (de ahora en adelante Tratado de 1967).

\section{B. Pregunta de investigación}

El Tratado de 1967 se creó sobre tres principios: uso pacífico del espacio ultraterrestre, no apropiación del espacio ultraterrestre y los cuerpos celestes ubicados en él y la cooperación internacional.

A lo largo de este trabajo de investigación se analizará la tensión que se genera entre el uso de satélites espía, o también llamados de inte- 
ligencia o de reconocimiento, y los principios anteriormente mencionados. Esas tensiones se evidencian cuando tenemos en cuenta que el espacio ofrece un ambiente ideal para transportar armas nucleares o cualquier otro tipo de armas de destrucción masiva de un país a otro sin que el blanco tenga la capacidad de prever el ataque, lo cual está expresamente prohibido por el Tratado de 1967; no obstante, ¿qué sucede cuando el objeto espacial colocado en este lugar no porta o no es un arma en sí, pero podría tener repercusiones en estrategias bélicas desarrolladas en la Tierra? Por otro lado, si tenemos en cuenta que gracias al principio de no apropiación no existe soberanía en el espacio ultraterrestre, ¿el hecho de que se esté observando el territorio de un Estado sin su consentimiento desde este lugar sí viola su soberanía? Finalmente, ¿la existencia de satélites espía afecta el desarrollo de la cooperación internacional debido a la desconfianza que puede generar? ¿Hay alguna forma de conciliar los satélites espía con la confianza que debe generar un comportamiento leal en el espacio ultraterrestre?

Todas estas oscuras cuestiones se resumen en la siguiente pregunta: ¿Los satélites espía estarían amparados por el derecho concerniente a la utilización del espacio ultraterrestre en conexidad con el derecho internacional?

Para darle una respuesta a la pregunta de investigación: 1) se explicará qué son los satélites espía; 2) se identificará el tratamiento que le ha dado el derecho internacional al espionaje y el derecho del espacio ultraterrestre a la militarización del espacio; 3) a partir de lo anterior, se concluirá el grado de legitimidad de los satélites espía; 4) se verificará si la realidad acerca del uso que se le está dando mundialmente a los satélites espía está en armonía con esta legitimidad; y 5), en caso de no estarlo se propondrá una solución para darle un uso correcto a los satélites espía o de inteligencia.

\section{ASPECTOS TÉCNICOS DE LOS SATÉLITES ESPÍA}

\section{A. Características y definición de los satélites espía}

\section{Qué es el espionaje}

De acuerdo con la Real Academia Española, espiar significa "acechar, observar disimuladamente a alguien o algo". Por otra parte, el analista militar Geoffrey Demarest lo define como la recolección consciente de información, ordenada por un Gobierno u organización hostil o sospechosa de aquellos a los cuales concierne dicha información, obtenida por humanos no autorizados por la víctima para realizar la recolección" (Demarest, 1996, p. 326). Michael Burn dilucida las siguientes características esenciales del espionaje: 1) se relaciona con la recolección de información acerca de sujetos u objetos recientemente observados; 2) el recolector envía la información de forma secreta; 3) la información es usada por individuos hostiles o sospechosos de aquellos sobre los cuales recae la información, y 4), generalmente, se piensa que es amenazante para el gobierno que la recolecta con los elementos anteriormente definidos, Burn 
define luego cuatro tipos de espionaje. Para este autor son: 1) el espionaje que un gobierno practica contra otro; 2) el espionaje usado para vencerlo; 3) la vigilancia secreta que un gobierno mantiene sobre sus propios ciudadanos; y 4), la vigilancia secreta que ciertos individuos mantienen sobre el gobierno (Burn, 1970). Para efectos del presente texto se hará referencia a los dos primeros tipos de espionaje.

\section{A qué género pertenecen los satélites espía}

Los satélites espía pertenecen al género de los satélites artificiales, estos son definidos como objetos espaciales, es decir, bienes muebles registrables que tienen como finalidad llegar al espacio ultraterrestre (Botero, 2013, p. 6), que se colocan en órbita alrededor de un cuerpo celeste como un planeta o un satélite natural. Existen varios tipos de satélites artificiales como los de telecomunicaciones, astronómicos y de teleobservación. A este último tipo de satélite pertenecen los satélites espías.

La teleobservación es definida como

[...] la observación de la superficie terrestre desde el espacio, utilizando las propiedades de las ondas electromagnéticas emitidas, reflejadas o difractadas por los objetos observados, para fines de mejoramiento de la ordenación de los recursos naturales, de utilización de tierras y de protección del medio ambiente. (ONU, 1986, Principio I)

Por tanto, estos satélites son los destinados a observar y fotografiar la Tierra para distintos fines.
El primer uso de los satélites de teleobservación es el manejo de los recursos naturales. Ferrer toma como ejemplos los siguientes: "Científicos británicos y de Arabia Saudita han determinado la viabilidad de localizar zonas de vegetación que son sitios potenciales de cría de langostas [...] En Japón se han utilizado los datos del satélite para el estudio de la contaminación del agua del mar interior de Seto" (Ferrer, 1976,. 390). El segundo uso es la prevención de desastres naturales. Por ejemplo, en 2012 Japón le propuso a la Asociación de Naciones del Sudeste Asiático la creación de una red de información conformada por pequeños satélites con la finalidad de prevenir desastres naturales. Estos fotografiarían la Tierra para identificar tifones y tsunamis (Nikkei, 2012). El tercer uso es la meteorología. Su misión es supervisar el tiempo atmosférico y el clima de la Tierra.

Finalmente, también se encuentra la facilitación de las actividades de cartografía y geografía como una de las funciones de este tipo de satélites pues, al tomar imágenes de la Tierra, se tiene una fuente exacta de cómo es el planeta y, así, diseñar mapas precisos.

\section{Cómo funcionan los satélites espía}

La recolección de información se hace mediante sensores, la parte esencial de un sistema de vigilancia. Este dispositivo es el que graba las imágenes de los objetos o señales generadas por ellos al detectar la radiación electromagnética reflejada por los objetos. ${ }^{1}$ Las imágenes

La radiación es "la energía ondulatoria o partículas materiales que se propagan a través del espacio" (RAE). La calidad y cantidad de 
recolectadas por los sensores pueden ser grabadas en película, ser convertidas en señales electromagnéticas y grabadas en magnetófono, o ser guardadas electrónicamente por dispositivos de carga acoplada (CCDs). En la primera de las posibilidades, la película puede ser traída de vuelta a la Tierra o desarrollada y escaneada en el satélite por dispositivos electrónicos y los resultados son transmitidos a la Tierra a través de microondas. La información registrada en un magnetófono o CCDs puede ser transmitida directamente a la Tierra cuando el satélite está dentro del rango de una estación terrestre de recolección de información, o a través de un dispositivo espacial distinto. La información luego es procesada en computadores para reconstruir las imágenes (ONU, 1991).

Por otra parte, los satélites espía operan en orbitas bajas a menos de $2000 \mathrm{~km}$ de la Tierra, puesto que la proximidad es apremiante para la calidad y nitidez de las imágenes. Estos satélites de reconocimiento óptico "solo ven realmente bien en una estrecha franja a sus pies, típicamente de unas decenas o algún centenar de kilómetros" (Cantó, 2009).

radiación reflejada por el objeto depende de su temperatura. "[...[ todo objeto cuya temperatura es superior al cero absoluto (-273 grados C) absorbe e irradia energía electromagnética en longitudes de onda particulares y características, la mayor parte de las cuales se encuentran fuera de la región visible del espectro. Estas características espectrales, una vez registradas, comparadas y analizadas, permiten distinguir los objetos entre sí, y obtener datos sobre su tamaño, forma, densidad y otras propiedades" (Ferrer, 1976, p. 394).

\section{4. ¿Qué tan nítida puede ser la imagen de un satélite espía?}

Hasta el siglo pasado un satélite a una altitud típica de $550 \mathrm{~km}$, podía obtener la máxima resolución efectiva de casi $13 \mathrm{~m}$, pero actualmente existen los satélites de alta resolución, los cuales pueden alcanzar resoluciones de 0,6 m, como lo hace el satélite comercial Quickbird (Cornejo, 2011).

De igual forma, Korody describe:

Un satélite espía estadounidense puede estar al tanto de los movimientos de los individuos en tierra, identificar carros, incluso leer la placa de los carros-todo esto mientras opera en cubierto a centenares de millas en el espacio y transmitiendo imágenes en tiempo real. (Korody, 2013, p. 1)

Lo anterior da cuenta que, por más alejados que estén de la Tierra, su capacidad de registrar sucesos terrestres es sorprendente.

En suma, el satélite espía puede ser considerado para efectos de este trabajo de investigación como un satélite de teleobservación de la Tierra, cuya función es recolectar información de los Estados de los cuales se sospecha para verificar que no se están tomando acciones que afecten las decisiones del Estado que observa. Con esta información, se pretende desarrollar actividades de planeación e inteligencia de las fuerzas armadas del Estado vigilante. 


\section{Clasificación de los satélites espía}

5.1. Los satélites de formación de imágenes: "utilizan la película, las cámaras electroópticas o el radar para producir imágenes de alta resolución de la superficie de la Tierra en distintas regiones del espectro [...] en algunos sistemas de satélites militares de la más alta resolución, para identificar diferentes tipos de vehículos y otro equipo y distinguir entre ellos. Quizás su aplicación más notable haya sido como medios técnicos nacionales de verificación de los acuerdos de limitación de armamentos". (ONU, 1994, p. 11)

\subsection{Los satélites de reconocimiento electrónico:} son los "oídos" en el espacio. "Ellos traen equipamiento diseñado para detectar y monitorear señales de radio generadas por las actividades militares del oponente [...] Estos satélites también recolectan datos de ensayos de misiles, radares nuevos, y muchos otros tipos de tráfico de comunicaciones". (ONU, 1994, p. 225)

\subsection{Los satélites de vigilancia del océano: detec-} tan y persiguen barcos y determinan las condiciones del mar que pueden, por ejemplo, ayudar a predecir el clima o detectar submarinos. Traen sensores que incluyen radares que pueden ver a través de las nubes y detectar incluso pequeños botes. (ONU,1994, p. 226)

\subsection{Los satélites militares para usos meteoroló-} gicos: pueden recolectar información sobre el clima a lo largo de la ruta de un misil determinado, y así, ser guiado con exactitud [...] la información recolectada [...] es más que solo la identificación de si un área de interés está cubierta de nubes, posibilitando el planeamiento de misiones de reconocimiento fotográfico o de bombardeo (ONU, 1994, p. 226).

\section{ASPECTOS JURÍDICOS DE LOS SATÉLITES ESPÍA}

Para definir qué tan acordes están los satélites espía con la normatividad concerniente a las actividades desarrolladas en el espacio ultraterrestre es necesario abordarlos a la luz del derecho internacional y de los instrumentos de derecho espacial que delimitan la regulación de la militarización del espacio ultraterrestre. A continuación se nombran y analizan.

\section{A. Espionaje en el derecho internacional}

Históricamente se ha visto al acto de espionaje como una actividad no ética e indeseable debido al secretismo que la envuelve. De hecho, este mismo concepto tiene otras definiciones como: "Intentar conseguir informaciones secretas sobre un país o una empresa" y "actividad dedicada a obtener información fraudulenta en diversos campos" (Demester, 1996).

Emmerich de Vattler ejemplifica la connotación peyorativa del espionaje al afirmar:

Los espías son generalmente condenados a un castigo capital, y no injustamente, pues nosotros hemos adquirido escasamente otros medios de protección contra las maldades que nos puedan ocasionar. Por esta razón, un hombre de honor, que no se expondría a morir a 
manos de un verdugo común, jamás declina servir de espía. Lo considera por debajo de él, como raras veces puede ser hecho con una especie de traición. (1996, p. 328)

Por su parte, Henry Halleck lo describe como "el disfraz que constituye la perfidia, y forma los elementos esenciales del crimen, los cuales, bajo las leyes de la guerra, es castigable con la más ignominiosa muerte" (Demarest, 1996).

Ahora que el concepto central del trabajo de investigación está claro, es preciso analizar cómo lo ha tratado el derecho internacional. El engaño, ya sea en tiempos de guerra o de paz, es el elemento esencial del espionaje; por esa razón, la dificultad de defender dicho engaño es la justificación primordial para permitir castigos severos contra el espionaje.

Respecto al espionaje en tiempos de guerra, el primer instrumento internacional en mencionarlo fue la Declaración de Bruselas estableciendo que las "estratagemas de guerra y el empleo de medios necesarios para procurar inteligencia respecto al enemigo o el Estado sujeto a las provisiones del Artículo XXXVI son considerados medios lícitos de guerra" (Declaración de Bruselas de 1874). Como bien se puede desprender de esta norma, la licitud de esta actividad se circunscribe solo a un marco de guerra y tal concepto como "espionaje" se equipara a "inteligencia”.

No obstante, la licitud de las actividades de inteligencia se diluye con la Convención de Génova (1949), la cual reza que en caso que se capture a un espía, este tiene derecho a un juicio junto con su respectiva apelación si la pena es impuesta, y un período de seis meses de suspensión de la sentencia antes que se pueda aplicar la pena de muerte. Además:

No obstante cualquier otra disposición de los Convenios o del presente Protocolo, el miembro de las fuerzas armadas de una Parte en conflicto que caiga en poder de una Parte adversa mientras realice actividades de espionaje no tendrá derecho al estatuto de prisionero de guerra y podrá ser tratado como espía. (Protocolo II de la Convención de Ginebra, art. 46)

Así, la codificación bélica apunta a la identificación de personas que no son espías mientras que nada establece acerca del espionaje como un crimen de guerra. Al contrario, el espionaje es aceptado como parte de la guerra, pero es reconocido como algo tan peligroso que la pena es autorizada como un medio desalentador.

Ahora bien, el derecho internacional no presenta ninguna herramienta que se refiera al espionaje en tiempos de paz. Sin embargo, la Carta de las Naciones Unidas nos da luces para concluir que el asunto cambia drásticamente con respecto a este acto en tiempos de guerra. La misma Carta de las Naciones Unidas dispone que:

Ninguna disposición de esta Carta autorizará a las Naciones Unidas a intervenir en los asuntos que son esencialmente de la jurisdicción interna de los Estados, ni obligará; a los Miembros a someter dichos asuntos a procedimientos de arreglo conforme a la presente Carta [...] (resaltado fuera del texto) 
Asimismo, en su artículo 39 establece que

el Consejo de Seguridad determinará la existencia de toda amenaza a la paz, quebrantamiento de la paz o acto de agresión y hará recomendaciones o decidirá qué medidas serán tomadas de conformidad con los Artículos 41 y 42 para mantener o restablecer la paz y la seguridad internacionales.

Siguiendo esta línea, el artículo 41 dispone:

El Consejo de Seguridad podrá decidir qué medidas que no impliquen el uso de la fuerza armada han de emplearse para hacer efectivas sus decisiones, y podrá instar a los Miembros de las Naciones Unidas a que apliquen dichas medidas $[\ldots]$.

Y el artículo 42 dice:

El Consejo de Seguridad podrá decidir qué medidas que impliquen el uso de la fuerza armada han de emplearse para hacer efectivas sus decisiones, y podrá instar a los Miembros de las Naciones Unidas a que apliquen dichas medidas [...].

Las normas anteriormente mencionadas dan cuenta de la acérrima intolerancia mundial al espionaje en tiempos de paz. En caso de que un Estado interfiera en los asuntos internos de otro, la Carta de las Naciones Unidas le da la facultad al Consejo de Seguridad para aplicar medidas tendientes a frenar dicha intervención. Esta acción no solo abarca acciones positivas de control y dirección de asuntos foráneos, sino también la observancia secreta de estos. De hecho, uno de los sinónimos que la Real Academia
Española da para "intervenir" es "espiar". Al fin y al cabo, la intervención se da en la medida en que la observancia secreta de los asuntos foráneos es el precursor de decisiones tomadas por el Estado espía en contra del Estado vigilado.

Para resumir el tratamiento del espionaje por parte del derecho internacional, válgase citar a Manuel García-Mora: “Aunque el derecho internacional no condena explícitamente el espionaje en tiempos de guerra, este en tiempos de paz es visto como un delito internacional y una violación al derecho internacional" (Demerest, 1996, p. 330, resaltado fuera del texto).

\section{B. Regularización de la militarización del espacio ultraterrestre}

Desde las primeras resoluciones de la Asamblea General en la materia "el interés común de la humanidad en la promoción del uso pacífico del espacio exterior" fue establecido, así como también "el interés común de la humanidad en promover los usos pacíficos del espacio ultraterrestre y la urgente necesidad del fortalecimiento de la cooperación internacional en este importante campo" (Resolución 1472 [XIV], 1959).

Estas preocupaciones fueron plasmadas en el Tratado sobre los principios que deben regir las actividades en el espacio ultraterrestre, también conocido como "la constitución del espacio". Este Tratado es el pilar sobre el cual se edifica todo el derecho del espacio ultraterrestre. Al ser un Tratado entra a ser hard law del derecho internacional, en virtud del artículo 38 del Estatuto de la Corte Internacional de Justicia, 
el cual establece cuatro fuentes a considerar cuando se estén tratando materias de derecho internacional, dentro de las cuales, la primera que se debe considerar es precisamente: “(a) convenciones internacionales, sean generales o especiales, que establezcan reglas expresamente reconocidas por los Estados litigantes [...]". El número de Estados que han ratificado este Tratado se acerca al centenar, “lo que demuestra que el Tratado pertenece a la categoría de instrumentos internacionales apoyados por una amplia mayoría de los integrantes de la comunidad internacional" (Kopal, 2009, p. 10).

No obstante, si bien la comunidad internacional en este Tratado reconoce "el interés general de toda la humanidad en el proceso de la exploración y utilización del espacio ultraterrestre con fines pacíficos", no se da una definición de "uso pacífico". Por esa razón, al ser instituido este principio surgieron dos interpretaciones: uno afirmando que el término excluye solo actividades de carácter "agresivo", pero no el uso "militar", y el otro que tanto uno como otro están prohibidos (Crane, 1962).

A favor de la primera concepción de uso pacífico se encuentra la Resolución 3314 de 1974 de la Asamblea General que recoge los trabajos de la Comisión para la definición de agresión, y que define dicho término como:

La agresión es el uso de la fuerza armada por un Estado contra la soberanía, la integridad territorial o la independencia política de otro Estado, o en cualquier otra forma incompatible con la Carta de las Naciones Unidas [...] cualquiera de los actos siguientes, independientemente de que haya o no declaración de guerra, se caracterizará como acto de agresión:

a) La invasión o el ataque por las fuerzas armadas de un Estado del territorio de otro Estado, o toda ocupación militar, aun temporal, que resulte de dicha invasión o ataque, o toda anexión, mediante el uso de la fuerza, del territorio de otro Estado o de parte de él;

b) El bombardeo, por las fuerzas armadas de un Estado, del territorio de otro Estado, o el empleo de cualesquiera armas por un Estado contra el territorio de otro Estado;

c) El Moqueo de los puertos o de las costas de un Estado por las fuerzas armadas de otro Estado;

d) El ataque por las fuerzas armadas de un Estado contra las fuerzas armadas terrestres, navales o aéreas de otro Estado, o contra su flota mercante o aérea;

g) La utilización de fuerzas armadas de un Estado, que se encuentran en el territorio de otro Estado con el acuerdo del Estado receptor, en violación de las condiciones establecidas en el acuerdo o toda prolongación de su presencia en dicho territorio después de terminado el acuerdo;

f) La acción de un Estado que permite que su territorio, que ha puesto a disposición de otro Estado, sea utilizado por ese otro Estado para perpetrar un acto de agresión contra un tercer Estado;

g) El envío por un Estado, o en su nombre, de bandas armadas, grupos irregulares o merce- 
narios que lleven a cabo sotos de fuerza armada contra otro Estado de tal gravedad que sean equiparables a los actos antes enumerados, o su sustancial participación en dichos actos.

Sin embargo, consideramos que la interpretación correcta de este principio es la que adopta la segunda postura. Manfred Lasch (2010), quien la defiende, argumenta que en caso que el uso pacífico solo excluyera actos agresivos, la mera referencia al derecho internacional y a la Carta de las Naciones Unidas bastaría, referencia contemplada en el Principio III del Tratado de 1967:

Los Estados Partes en el Tratado deberán realizar sus actividades de exploración y utilización del espacio ultraterrestre, incluso la Luna y otros cuerpos celestes, de conformidad con el derecho internacional, incluida la Carta de las Naciones Unidas, en interés del mantenimiento de la paz y la seguridad internacionales y del fomento de la cooperación y la comprensión internacionales. (Resaltado fuera del texto)

Además, las palabras adicionales "para fines pacíficos" contempladas en el artículo IV habrían sido redundantes.

Asimismo, si bien el Tratado no da una definición clara de este principio, otros instrumentos que son el desarrollo de este Tratado sí la dan y su interpretación es inequívoca. El Acuerdo sobre las actividades que deben regir las actividades en la Luna y otros cuerpos celestes reza en su artículo 3:
1. Todos los Estados Partes utilizarán la Luna exclusivamente con fines pacíficos.

2. Se prohíbe recurrir a la amenaza o al uso de la fuerza, asi como a otros actos hostiles o a la amenaza de estos actos, en la Luna. Se prohíbe también utilizar la Luna para cometer tales actos o para hacer tales amenazas con respecto a la Tierra, a la Luna, a naves espaciales, a tripulaciones de naves espaciales o a objetos espaciales artificiales. (Resaltado fuera del texto)

Este Acuerdo sostiene que queda prohibido, no solo los actos no agresivos, sino también cualquier tipo de acto hostil y la amenaza de dichos actos. Consideramos que la militarización del espacio per se implica la amenaza de que en cualquier momento se podrán utilizar para un potencial acto agresivo. Por tanto, el alma de este Acuerdo, y por ende, la del Tratado de 1967, establecen que el principio de uso pacífico excluye tanto los actos agresivos como los usos militares de carácter no agresivo que se le den al espacio ultraterrestre.

De hecho, esta interpretación tiene varios antecedentes. Un ejemplo es la provisión concerniente a "la contribución de la energía atómica a la paz, la salud y la prosperidad en todo el mundo" conectada a que dicha energía no se utilizará "en forma tal que contribuya a fines militares" (Estatuto de la Agencia para la Energía Nuclear, 1956, art. II, resaltado fuera del texto). En el Tratado Antártico el término "fines pacíficos" está relacionado con la prohibición de "cualquier medida de naturaleza militar" (Tratado Antártico, 1959, art. I). Finalmente, en este mismo 
Tratado se establece como uso no pacífico: “[...] inter alia, cualquier medida de naturaleza militar como el establecimiento de bases militares o fortificaciones, la realización de maniobras militares así como los ensayos de cualquier tipo de armas".

Siguiendo esta misma postura se encuentra el doctrinante Stephen Gorove. Primero, parte del artículo IV del Tratado de 1967 que reza:

Los Estados Partes en el Tratado se comprometen a no colocar en órbita alrededor de la Tierra ningún objeto portador de armas nucleares ni de ningún otro tipo de armas de destrucción en masa, a no emplazar tales armas en los cuerpos celestes y a no colocar tales armas en el espacio ultraterrestre en ninguna otra forma [...] Queda prohibido establecer en los cuerpos celestes bases, instalaciones y fortificaciones militares, efectuar ensayos con cualquier tipo de armas y realizar maniobras militares [...] Tampoco se prohíbe la utilización de cualquier equipo o medios necesarios para la exploración de la Luna y de otros cuerpos celestes con fines pacíficos.

Luego dice:

Mientras todo parece indicar que los legisladores del Artículo IV no determinaron "pacífico" como "no militar", por lo menos en este contexto, un escrutinio más profundo del mismo artículo sugiere que tampoco entendieron "pacífico" como "no agresivo". Esto se vuelve aparente desde la estipulación de la oración "efectuar ensayos con cualquier tipo de armas y realizar maniobras militares” están prohibidos incluso si dichas actividades son de naturaleza "no agresiva" (ONU, 1984, pp. 82, 83).
(Resaltado fuera del texto)

No obstante, este doctrinante también afirma que en la interpretación dada sobre este principio, por ejemplo, en el Acuerdo sobre las actividades que deben regir las actividades en la luna y otros cuerpos celestes

parece dudoso afirmar que el uso pacífico se refiera exclusivamente a la desmilitarización completa. Si todas las armas estuvieran de hecho prohibidas, no parece ser mucho más inmediata la necesidad de prohibir el uso de la fuerza o de actos hostiles sin armas. Aunque es concebible, pero no es muy probable, esto todavía puede haber sido el objetivo deseado. (ONU, 1984, p. 86)

Esta duda se resuelve con el artículo 51 de la Carta de las Naciones Unidas:

Ninguna disposición de esta Carta menoscabará el derecho inmanente de legítima defensa, individual o colectiva, en caso de ataque armado contra un Miembro de las Naciones Unidas, hasta tanto que el Consejo de Seguridad haya tomado las medidas necesarias para mantener la paz y la seguridad internacionales. Las medidas tomadas por los Miembros en ejercicio del derecho de legítima defensa serán comunicadas inmediatamente al Consejo de Seguridad [...].

Al igual que Lasch (2010), afirmamos que este artículo supone que el derecho de legítima defensa es la única excepción a la regla general que el principio de uso pacífico significa completa desmilitarización del espacio ultraterrestre, ya sea mediante actos militares agresivos o no agresivos. 


\section{Legalidad del uso de satélites espía}

La regulación del derecho internacional y del derecho del espacio ultraterrestre frente al espionaje y a la militarización del espacio, respectivamente, nos da a entender que la regla general es que el uso de satélites espía está prohibido y la única excepción a este respecto es el derecho a la legítima defensa instituido en el artículo 51 de la Carta de las Naciones Unidas. Para argumentar esta posición se utilizarán los principios establecidos por el Tratado de 1967 y los Principios relativos a la teleobservación de la Tierra desde el espacio pues, como ya se dijo, los satélites espía son una especie de satélites de teleobservación de la Tierra.

Primero, es claro que de acuerdo con el derecho internacional el uso de satélites espía en tiempos de paz es impensable. Observar secretamente a otro Estado es intervenir en sus asuntos internos pues se estarían tomando decisiones potencialmente perjudiciales para el Estado observado a partir de la vigilancia subrepticia de sus asuntos.

Relacionando esta prohibición con el derecho del espacio ultraterrestre, se recuerda que el artículo III del Tratado del 1967 ordena que las actividades llevadas a cabo en este escenario deben realizarse "de conformidad con el derecho internacional, incluida la Carta de las Naciones Unidas". Por su parte, el Principio III relativo a la teleobservación de la Tierra también establece que "las actividades de teleobservación se realizarán de conformidad con el derecho internacional, inclusive la Carta de las Naciones Uni- das". Por consiguiente, se debe cumplir con los preceptos que prohíben el espionaje en tiempos de paz.

En caso de contravenir lo anterior, se estaría vulnerando el principio de uso pacífico del espacio ultraterrestre pues este supone la completa desmilitarización del espacio, como ya se argumentó previamente. Sistemas de reconocimiento y vigilancia en pos de reforzar estrategias militares terrestres, como lo son los satélites espía, implican per se una amenaza latente para los Estados observados, por tanto, su uso es netamente militar sin atisbo alguno de que se pueda interpretar como no excluido por el principio de uso pacífico.

Asimismo, mediante la contravención a los preceptos que prohíben el espionaje en tiempos de paz también se vulneraría el principio de cooperación internacional del Tratado de 1967. “La cooperación depende de la confianza existente en las relaciones entre los Estados que estén dispuestos a cooperar, y de que esa confianza aumente con el tiempo, a medida que la conducta de los Estados demuestre su disposición a comportarse de manera cooperativa" (ONU, 1994, p. 30). En conexidad con esto, se tiene que el proceso de confianza se desarrolla mediante lo siguiente:

La eliminación de las causas de desconfianza, temor, malentendidos y errores de cálculo por lo que respecta a las actividades suyas relativas a la seguridad. Este proceso se basa en la premisa de reconocer que todo Estado necesita garantías de que determinadas actividades militares o relativas a la seguridad realizadas 
por otros Estados no constituyen una amenaza para su propia seguridad (1994).

A partir de la concepción que tiene la Asamblea General acerca de la confianza y la cooperación entre Estados, se concluye que el engaño en el que se basa la actividad del espionaje impide la construcción de la confianza y, por ende, se viola el principio de cooperación internacional. El espionaje implica que el Estado observado siempre vea su seguridad amenazada por parte de la vigilancia del Estado que lo observa. Dado que dicha vigilancia es secreta, el Estado observado no sabrá en qué momento un Estado intervendrá en sus asuntos internos mediante un sistema espacial de vigilancia o reconocimiento. En suma, las garantías de que actividades militares no estarán amenazando su seguridad interna se desvanecen.

Por esa razón, el desarrollo de la confianza en el ámbito del derecho del espacio ultraterrestre se centra específicamente en la creación de garantías que aseguren la inexistencia de potenciales ataques bélicos en el espacio. En el espacio los satélites de inteligencia o de vigilancia y reconocimiento tienen la capacidad de "penetrar en todos los puntos de la Tierra, para muy diversos fines civiles y militares. Esta capacidad de intrusión, incluso en los casos que no entrañe armamentos, puede generar desconfianza" (ONU, 1994, p. 36).

Para materializar estas garantías, Vladimir Kopal recuerda que en el reporte de la primera conferencia de las Naciones Unidas sobre la exploración y los usos pacíficos del espacio ul- traterrestre, el cual fue adoptado por consenso, por lo que resultaría vinculante para todos los Estados debido a que supone el consenso, implica que todos acepten la decisión en todos sus alcances a pesar de no estar de acuerdo, ${ }^{2}$ se estableció que:

la extensión de una carrera armamentista en el espacio exterior fue calificada como un "asunto de gran preocupación en la comunidad internacional" y como "perjudicial para la humanidad en su conjunto"; por lo tanto, debería ser prevenida. Todas las naciones, en particular los que poseían una capacidad superior para realizar actividades en el espacio exterior, instaron a "contribuir activamente al objetivo de impedir una carrera de armamentos en el espacio ultraterrestre para frenar cualquier acción contraria a ese objetivo". Además, se subrayó que “la prevención de una carrera de armamentos en el espacio ultraterrestre y de las hostilidades es un requisito esencial para la continuidad y el avance de la cooperación internacional en la exploración y utilización del espacio ultraterrestre con fines pacíficos". A este respecto, la Conferencia instó a todos los Estados al Tratado de 1967 y observar estrictamente su letra y el espíritu. (Kopal, 1984, pp. 69-70)

Generalmente, las resoluciones se consideran soft law; no obstante, existe una postura que afirma que estas tienen fuerza vinculante si son adoptadas por consenso porque este se entiende como un acuerdo general sobre un tema en particular, por lo que supone que todos sus intervinientes están de acuerdo son la decisión adoptada; diferente al sistema de voto, que implica una elección por alternativa o exclusión. Así, el consenso es "una convicción sobre la conveniencia o acierto de una proposición dada [...] supone la aceptación de la opción en todo su alcance y además un sentimiento, a su respecto, que es común por parte de quienes la eligen (Cocca, 1991, p. 48). Si todos aceptan la decisión en todo su alcance, entonces su obediencia supone costumbre internacional que sí es vinculante de acuerdo al artículo 38 de la Convención de Viena sobre Derecho de los Tratados. "La costumbre actúa como norma imperativa y por lo tanto es ius cogens dado que la costumbre en el plano internacional y en el derecho del espacio ultraterrestre, goza de una fuerza coercitiva, inclusive que las normas positivas" (Franco, 2013, p. 46). 
Por su parte, el Principio V de los Principios Relativos a la Teleobservación de la Tierra dice: “Los Estados que realicen actividades de teleobservación promoverán la cooperación internacional en esas actividades. Con tal fin, esos Estados darán a otros Estados oportunidades de participar en esas actividades. Esa participación se basará en cada caso en condiciones equitativas y mutuamente aceptables". (Resaltado fuera del texto). La participación que se le otorga al Estado observado en las actividades de teleobservación provienen precisamente de prevenir la desconfianza y la vulneración del principio de cooperación internacional mediante falta de conocimiento acerca de cuándo es que el territorio de algún Estado está siendo observado y para qué fines.

Por lo anterior es que el Principio XIII de este documento reza:

Tan pronto como sean producidos los datos primarios y los datos elaborados que correspondan al territorio bajo su jurisdicción, el Estado objeto de la teleobservación tendrá acceso a ellos sin discriminación y a un costo razonable. Tendrá acceso asimismo, sin discriminación y en idénticas condiciones, teniendo particularmente en cuenta las necesidades y los intereses de los países en desarrollo, a la información analizada disponible que corresponda al territorio bajo su jurisdicción y que posea cualquier Estado que participe en actividades de teleobservación. (Resaltado fuera del texto)

Al tener acceso a la información obtenida por los satélites de teleobservación, se genera confianza, y por tanto cooperación, entre los Estados al evitar actividades oscuras y comportamientos inesperados por parte de estos. No obstante, la información obtenida por satélites espía no se le comunican al Estado observado. Esto supone que se genere la desconfianza a partir de la falta de conocimiento acerca de las decisiones que tomará el Estado vigilante respecto a la información obtenida.

Ahora bien, como ya se ha adelantado, no todo es prohibición en esta materia. Para explicar la excepción en este tema, permítase comenzar por el artículo II del Tratado de 1967: “El espacio ultraterrestre, incluso la Luna y otros cuerpos celestes, no podrá ser objeto de apropiación nacional por reivindicación de soberanía, uso u ocupación, ni de ninguna otra manera". El principio de no apropiación es el último pilar jurídico del derecho del espacio ultraterrestre. Se decidió de esta manera porque el fantasma de las más de 150000 almas japonesas que habían muerto por causa de la chocante bomba atómica aún despertaba el remordimiento y el miedo de la comunidad internacional. La Ilegada del hombre al espacio trajo consigo la creencia de que podría existir una nueva guerra mundial de resultados catastróficos si se utilizaba el espacio para fines bélicos; un tratado que impidiera cualquier posibilidad de que se usara el espacio ulterior como lugar ventajoso para aprovechar la escatológica fuerza de la energía nuclear era inminente para impedir la muerte de más personas inocentes. Y claro, dicho tratado debía ser expreso y claro en ordenar la prohibición de una guerra más allá de la atmósfera. 
El principio de no apropiación es la expresión que consolida el deseo de la comunidad internacional de utilizar siempre el espacio ultraterrestre con fines pacíficos, como bien se plasma en las cláusulas motivas del Tratado de $1967 .{ }^{3}$ Al respecto tenemos que este principio y la primera cláusula motiva del Tratado de 1967 que dice "Reconociendo el interés general de toda la humanidad en el proceso de la exploración y utilización del espacio ultraterrestre con fines pacíficos" (resaltado fuera del texto), lleva a concluir que este es un espacio que le pertenece a toda la humanidad en lugar de ser res nullius. Este es un espacio abierto a toda la humanidad para su exploración y los distintos Estados. La conclusión forzosa de esto es "la proclamación de un espacio no estatal, el espacio ultraterrestre es un espacio que no es de los Estados, sino de la humanidad" (Camargo, 2003, p. 149).

En tanto le pertenece a toda la humanidad no hay manera de que un Estado proclame soberanía sobre algún cuerpo celeste o parte del espacio. Si no hay soberanía, tampoco existe un potencial derecho de legítima defensa. Si no hay derecho de legítima defensa, quien decida ha-

3 Estas cláusulas estipulan:

Reconociendo el interés general de toda la humanidad en el proceso de la exploración y utilización del espacio ultraterrestre con fines pacíficos,

Estimando que la exploración y la utilización del espacio ultraterrestre se debe efectuar en bien de todos los pueblos, sea cual fuere su grado de desarrollo económico y científico,

Deseando contribuir a una amplia cooperación internacional en lo que se refiere a los aspectos científicos y jurídicos de la exploración y utilización del espacio ultraterrestre con fines pacíficos,

Estimando que tal cooperación contribuirá al desarrollo de la comprensión mutua y al afianzamiento de las relaciones amistosas entre los Estados y pueblos (ONU, 1967). (Resaltado fuera del texto). cer del espacio un escenario bélico estará contrariando el derecho internacional.

Pero el concepto de soberanía cambia en el ámbito terrestre. En el espacio intraplanetario podemos entender este concepto desde una configuración del sistema internacional a partir de “la distinción entre el poder como la capacidad de actuar propiamente dicha y el derecho, o la ley, como la capacidad de regularse internamente un Estado. El sistema debe entenderse como aquel espacio en el que cada Estado actúa enfrentado a lo que quieren o pueden hacer otros Estados, interna o externamente afectando la vida y organización de todos los interactuantes" (Camargo, 2003, p. 24) Así, Botero llega a concluir que entonces la soberanía es el "atributo del Estado que permite a éste, por conducto de los gobiernos, el ejercicio de los poderes real y jurídico de forma que imponga a los asociados conductas o líneas de acción político-social y la capacidad efectiva de hacer cumplir estas conductas" (Botero, 1996, p. 198).

El concepto de soberanía terrestre, por tanto, supone que los Estados no pueden afectar la vida y organización de los ciudadanos u organismos gubernamentales de otros Estados en tanto son estos los que deben tener la capacidad de actuar y regularse autónomamente para decidir sus propias líneas de acción político-sociales y jurídicas. Cuando en la Tierra se viola este derecho, ¿puede el Estado víctima utilizar satélites en un espacio perteneciente a toda la humanidad para realizar actividades de inteligencia, reconocimiento y vigilancia sobre el Estado infractor para desarrollar sus estrategias militares en 
Tierra en virtud del derecho de legítima defensa consagrado en la Carta de las Naciones Unidas? Consideramos que sí y, por ende, este es el único fin por el que se podría utilizar un satélite espía o de inteligencia.

Primero, el derecho internacional acepta las actividades de espionaje en tiempos de guerra aunque no sean deseables. Por ende, en caso que un Estado utilizara sus satélites espía para este fin estaría actuando acorde con el derecho internacional y la Carta de las Naciones Unidas. Segundo, los satélites espía no tienen repercusiones bélicas dentro del espacio ultraterrestre, como sí lo harían armas nucleares o cualquier otro tipo de armas expresamente prohibidas en el Principio IV del Tratado de 1967 y otros instrumentos como el Acuerdo que Debe Regir las Actividades en la Luna y otros Cuerpos Celestes. ${ }^{4}$ Si bien estos satélites tienen fines netamente militares, estos no se dan en el espacio de la humanidad que debe estar libre de guerras en todo momento, sino en la Tierra, donde sí se podría vulnerar la soberanía en virtud del derecho a la legítima defensa.

En conclusión, en tiempos de paz se debe prohibir los satélites espía pues su uso vulneraría la soberanía de los Estados pues se estaría interfiriendo en la capacidad de los demás Estados de autorregularse y darse sus propias decisiones sin repercusiones perjudiciales. El Principio IV

4 Los Estados Partes no pondrán en órbita alrededor de la Luna, ni en otra trayectoria hacia la Luna o alrededor de ella, objetos portadores de armas nucleares o de cualquier otro tipo de armas de destrucción en masa, ni colocarán o emplearán esas armas sobre o en la Luna (art. 3, n. 3). de los Principios que Deben Regir la Teleobservación de la Tierra ejemplifica esto:

Las actividades de teleobservación se realizarán de conformidad con los principios contenidos en el artículo I del Tratado sobre los principios que deben regir las actividades de los Estados en la exploración y utilización del espacio ultraterrestre, incluso la Luna y otros cuerpos celestes, en el cual se dispone en particular [...] el principio de que el espacio ultraterrestre estará abierto para su exploración y utilización en condiciones de igualdad. Estas actividades se realizarán sobre la base del respeto del principio de la soberanía plena y permanente de todos los Estados y pueblos sobre su propia riqueza y sus propios recursos naturales, teniendo debidamente en cuenta los derechos e intereses, conforme al derecho internacional, de otros Estados y entidades bajo la jurisdicción de estos. (Resaltado fuera del texto)

En tiempos de guerra, la vulneración de la soberanía de los Estados en virtud de la utilización de satélites espía se vería legitimada por la misma Carta de las Naciones Unidas.

En suma, se tienen dos presupuestos con respecto a los satélites espía: 1) Existe un trato diferenciado entre los satélites espía y otras armas o tecnologías de destrucción masiva en el espacio, las cuales están prohibidas completamente. 2) Se acepta su uso si de apoyo a actividades militares en la Tierra se trata porque, al fin y al cabo,

Ios satélites pueden proveer planes militares con información actual y exacta de la situación 
y los movimientos de los blancos, la topografía y las condiciones climáticas, y ayudan a prevenir ataques sorpresivos [...] Los satélites continúan siendo un esencial medio de explotación de la vulnerabilidad del enemigo, y por ende, mejorar el poder militar. (Al-Rodhan, 2012, p. 51)

Esto da cuenta de su gran importancia a la hora de contraatacar para defender la soberanía violada. Y 3), se ordena limitar su uso en cuanto este es tan solo una excepción a la regla general. Tristemente, la realidad siempre ha sido otra.

\section{REALIDAD SOBRE EL USO DE LOS SATÉLITES ESPÍA}

Si bien el uso de los satélites espía debería estar limitado, la verdad es que su uso ha sido tan común que nuestro planeta pareciera ser un gran panóptico. Este es:

En la periferia, una construcción en forma de anillo; en el centro, una torre, ésta, con anchas ventanas que se abren en la cara interior del anillo. La construcción periférica está dividida en celdas, cada una de las cuales atraviesa toda la anchura de la construcción. Tienen dos ventanas, una que da al interior, correspondientes a las ventanas de la torre, y la otra, que da al exterior, permite que la luz atraviese la celda de una parte a otra. Basta entonces situar a un vigilante en la torre central [...] Por el efecto de la contraluz, se pueden percibir desde la torre, recortándose perfectamente sobre la luz, las pequeñas siluetas cautivas en las celdas de la periferia. (Foucault, 2003, p. 184)
En la cima de la torre central, en aquel espacio ultraterrestre tan inalcanzable para los ojos humanos, hay centenares de invisibles satélite espía. En la Tierra, los habitantes del planeta están condenados a renunciar a la privacidad.

Los primeros satélites en usarse fueron Corona, Argon y Lanyard por parte de Estados Unidos. Las imágenes fueron originalmente utilizadas para reconocimiento de territorios foráneos a suelo norteamericano y producir mapas para las agencias de inteligencia de Estados Unidos. Esta generación de satélites recolectó más de 860000 imágenes de la superficie de la Tierra entre 1960 y 1972 como se muestra a continuación: 


\begin{tabular}{|c|c|c|c|c|}
\hline \multicolumn{5}{|c|}{ Parámetros de las misiones } \\
\hline Sistema satelital & $\begin{array}{c}\text { Designador de la } \\
\text { misión }\end{array}$ & $\begin{array}{l}\text { Misiones } \\
\text { exitosas }\end{array}$ & $\begin{array}{c}\text { Períodos de adquisición de } \\
\text { videos }\end{array}$ & $\begin{array}{c}\text { Mejor resolución del } \\
\text { suelo }\end{array}$ \\
\hline CORONA & $\mathrm{KH}-1$ & 9009 & $8 / 1960$ & 40 pies \\
\hline CORONA & $\mathrm{KH}-2$ & $\begin{array}{l}9009 \\
9017 \\
9019\end{array}$ & $12 / 1960-7 / 1961$ & 30 pies \\
\hline CORONA & $\mathrm{KH}-3$ & $\begin{array}{l}9022 \\
9023 \\
9025 \\
9028 \\
9029\end{array}$ & 8/1961-12/1961 & 25 pies \\
\hline CORONA & $\mathrm{KH}-4$ & $\begin{array}{c}9031-9032 \\
9035 \\
9037-9041 \\
9043-9045 \\
9047-9048 \\
9050-9051 \\
9053-9054 \\
9056-9057 \\
9062\end{array}$ & $2 / 1962-12 / 1963$ & 25 pies \\
\hline CORONA & $\mathrm{KH}-4 \mathrm{~A}$ & $\begin{array}{c}1001-1002 \\
1004 \\
1006-1031 \\
1033-1052\end{array}$ & 8/1963-9/1969 & 9 pies \\
\hline CORONA & $\mathrm{KH}-4 \mathrm{~B}$ & $\begin{array}{l}1101-1112 \\
1114-1117 \\
\end{array}$ & 9/1967-5/1972 & 6 pies \\
\hline ARGON & $\mathrm{KH}-5$ & $\begin{array}{l}9034 A \\
9046 A \\
9058 A \\
9059 A \\
9065 A \\
9066 A\end{array}$ & $5 / 1962-8 / 1964$ & 460 pies \\
\hline LANYARD & $\mathrm{KH}-6$ & 8003 & $7 / 1963-8 / 1963$ & 6 pies \\
\hline
\end{tabular}

(Science for a Chaning World, 2014)

Charleston (2010) recuerda que esta primera generación de satélites espía marcó una revolución en las actividades de inteligencia. Era un momento en que todavía la dificultad extraordinaria para reunir información por cualquier otro medio de agrupación de "áreas negadas", in- cluyendo la Unión Soviética, la China comunista y sus aliados. La necesidad de información de inteligencia sobre los sistemas y bases de datos soviéticos aumentó drásticamente cuando dicho país tomó como prisionero a Gary Powers. Este fue un agente de la CIA que de 1956 a 
1960 voló el avión U-2 regularmente sobre territorio de la Unión Soviética recogiendo información inmensamente valiosa para la milicia estadounidense. En 1960, los soviéticos derribaron el avión y capturaron a su piloto. Gary Powers fue considerado un espía, y por esa razón estuvo condenado a tres años de cárcel y siete de trabajos forzados hasta que fue objeto de intercambio por el coronel ruso Vilyan Fisher (Demester, 1996). A los pocos meses, sin embargo, el 18 de agosto de 1960, Estados Unidos lanzó su primer satélite de reconocimiento, el cual, en una sola misión tuvo mayor cobertura fotográfica de la Unión Soviética que todas las misiones del U-2 en su conjunto.

Los soviéticos no se quedaron atrás, impulsados por el fragor de la Guerra Fría, entre 1960 y 1992, también tuvieron su propio programa de satélites espía llamados Zenith. Entre otros, en 1966 fueron lanzados tres satélites Zenith, en 1967 fue lanzado uno, entre 1968 y 1971 fueron lanzados cuatro, dos en 1974 y otros cuatro en 1990.5

De igual forma, Richard Weitz describe:

El Pentágono usa recursos espaciales para las comunicaciones, reconocimiento, navegación, focalización de blancos militares, y otras actividades militares centrales, mientras los satélites proveen información vital a la comunidad de inteligencia estadounidense. Estos recursos son esenciales para las misiones estadounidenses de seguridad nacional, incluyendo la realización de operaciones de combate, verifi-

5 Recuperado de: http://www.cosmonautica.es/12a.pdf 6/04/2014. cación de Acuerdos sobre control de armamento, análisis de desarrollos extranjeros de defensa, y el monitoreo de condiciones ambientales a largo plazo. (Al-Rodhan, 2012, p. 110)

El 6 de diciembre de 2013 el diario International Business Times publicó la noticia del lanzamiento de un posible satélite espía desde California. Este diario afirmó que la estación de lanzamiento llevaba una carga clasificada y la participación de la Oficina Nacional de Reconocimiento en el lanzamiento había causado rumores de que se tratara de un satélite espía. ${ }^{6}$

Asimismo, actualmente se encuentran en órbita el sistema satelital NOAA, que actualmente le sirve al Programa Satelital Meteorológico de Defensa de Estados Unidos (DMSP). Cada uno de estos satélites, los cuales orbitan a aproximadamente $830 \mathrm{~km}$ de la Tierra, cruza cualquier punto del planeta dos veces al día. Observan fenómenos meteorológicos tales como nubes, cuerpos de agua, nieve, fuego y polución en el espectro visual e infrarrojo. Comunicados a terminales en tierra, los datos son procesados e interpretados por meteorólogos y usados para planeación y operaciones militares de las Fuerzas Armadas de Estados Unidos alrededor del mundo (COF, 2014).

Otro satélite espía fue lanzado en el 2008 desde India. El Ministerio de Defensa de Israel

6 An Atlas $\vee$ rocket was successfully launched from California's Vandenberg Air Force Base Thursday night at 11:15 p.m. PST. While a successful rocket launch is one thing, the fact the Atlas $V$ was carrying a classified payload, and the involvement of the National Reconnaissance Office, has led many to speculate that the rocket was carrying spy satellites. (IBT, 2013) Recuperado de http://www.ibtimes.com/ secret-spy-satellites-launched-national-reconnaissance-office-atlas-vrocket-carries-classified 
anunció que el Ofek 9 había sido lanzado desde la base de la Fuerza Aérea de Palmachim. Ese fue el cuarto satélite espía de Israel para vigilar a Irán, pues lo consideraba como la amenaza principal de su seguridad luego de repetidas referencias por parte de líderes iraníes acerca de la "desaparición de Israel", lo que conllevó a pensar que estaban desarrollando armas nucleares (ATFP, 2013).

China no se queda atrás y actualmente tiene un fuerte programa de satélites espía llamados los Yaoang. Este programa incluye satélites electrópticos (EO) con radares de abertura sintéticos (SAR); satélites para imágenes nocturnas e inteligencia electrónica (ELINT); satélites para localizar e identificar barcos por sus emisiones electrónicas, entre otros. Como ejemplo de este programa se encuentra el Yaogan 9, que fue lanzado el 5 de marzo de 2010 con la función de reconocimiento marítimo. El 25 de noviembre se lanzó el Yaogan 16 y el $1^{\circ}$ de septiembre de 2013 se lanzó el Yaogan 17 con la misma función. El Tian Hui, lanzado el 24 de agosto de 2010 para trazar mapas militares y el Tian Hui 1B, el 6 de mayo de 2012 para el mismo fin (Easton, 2014, p. 10).

En suma, como bien dice Bruce Deblois, "si bien no está armamentarizado, el espacio está totalmente militarizado" (Deblois, 1984, p. 15). De esto da cuenta el decrecimiento progresivo de registro de los objetos espaciales. Primero, el artículo XI del Tratado de 1967 dice:

A fin de fomentar la cooperación internacional en la exploración y utilización del espacio ultra- terrestre con fines pacíficos, los Estados Partes en el Tratado que desarrollan actividades en el espacio ultraterrestre, incluso la Luna y otros cuerpos celestes, convienen en informar, en la mayor medida posible dentro de lo viable y factible, al Secretario General de las Naciones Unidas, así como al público y a la comunidad científica internacional, acerca de la naturaleza, marcha, localización y resultados de dichas actividades. El Secretario General de las Naciones Unidas debe estar en condiciones de difundir eficazmente tal información, inmediatamente después de recibirla. (Resaltado fuera del texto)

Asimismo, el Convenio Sobre el Registro de Objetos Lanzados al Espacio Ultraterrestre, establece en su artículo II:

Cuando un objeto espacial sea lanzado en órbita terrestre o más allá, el Estado de lanzamiento registrará el objeto espacial por medio de su inscripción en un registro apropiado que llevará a tal efecto. Todo Estado de lanzamiento notificará al Secretario General de las Naciones Unidas la creación de dicho registro. Resaltado fuera del texto)

Siguiendo esto, en su artículo IV reza:

Todo Estado de registro proporcionará al Secretario General de las Naciones Unidas, en cuanto sea factible, la siguiente información sobre cada objeto espacial inscrito en su registro:

a) Nombre del Estado o de los Estados de lanzamiento;

b) Una designación apropiada del objeto espacial o su número de registro; 
c) Fecha y territorio o lugar del lanzamiento;

d) Parámetros orbitales básicos, incluso:

i) Período nodal;

ii) Inclinación;

iii) Apogeo;

iv) Perigeo.

e) Función general del objeto espacial

Finalmente, los Principios Relativos a la Teleobservación de la Tierra desde el Espacio, presenta en su principio IX:

De conformidad con el artículo IV del Convenio sobre el registro de objetos lanzados al espacio ultraterrestre y con el artículo XI del Tratado sobre los principios que deben regir las actividades de los Estados en la exploración y utilización del espacio ultraterrestre, incluso la Luna y otros cuerpos celestes, el Estado que realice un programa de teleobservación informará de ello al Secretario General de las Naciones Unidas. Comunicará también, en la mayor medida posible dentro de lo viable y factible, toda la demás información pertinente a cualquier Estado, y especialmente a todo país en desarrollo afectado por ese programa, que lo solicite.

Pero cada vez más, los Estados lanzan objetos espaciales sin notificarle al Secretario de las Naciones Unidas dicho lanzamiento con las especificaciones dadas en el convenio, tal como lo muestra la siguiente tabla:
Número de objetos espaciales

\begin{tabular}{|c|c|c|c|}
\hline Años & Lanzamientos & Registro & Porcentaje \\
\hline $1976-1980$ & 587 & 582 & $99 \%$ \\
\hline $1981-1985$ & 780 & 756 & $97 \%$ \\
\hline $1986-1990$ & 707 & 671 & $95 \%$ \\
\hline $1991-1995$ & 593 & 542 & $91 \%$ \\
\hline $1996-2000$ & 657 & 511 & $78 \%$ \\
\hline $2001-2003$ & 269 & 201 & $75 \%$ \\
\hline
\end{tabular}

(laninni, 2012, p. 31)

La falta de registro de objetos espaciales ante el Secretario de las Naciones Unidas se debe a que los Estados no desean que se conozcan las funciones de los satélites que lanzan al espacio. Si el engaño y el secreto son la base del espionaje, la falta de notificación a las Naciones Unidas es totalmente acorde con el lanzamiento de satélites espía, lo cual explicaría este fenómeno.

Tanto secretismo en un lugar en el que la cooperación es esencial para su utilización en beneficio de la humanidad es perjudicial para la consolidación de relaciones amistosas entre los Estados, y por ende, también para el mantenimiento del espacio ultraterrestre como un lugar pacífico. A continuación se presenta una propuesta para utilizar las ventajas de los satélites espía en armonía con la normatividad del derecho del espacio ultraterrestre. 


\section{LA CORRECTA UTILIZACIÓN DE LOS SATÉLITES ESPÍA: DE VISIÓN LOCAL A VISIÓN GLOBAL DE LA SEGURIDAD}

Para presentar nuestra propuesta respecto a cómo se deberían utilizar los satélites espía es pertinente comenzar por las dos primeras cláusulas motivas del Tratado de 1967:

Inspirándose en las grandes perspectivas que se ofrecen a la humanidad como consecuencia de la entrada del hombre en el espacio ultraterrestre,

Reconociendo el interés general de toda la humanidad en el proceso de la exploración y utilización del espacio ultraterrestre con fines pacíficos [...]. (Resaltado fuera del texto)

Nuestra propuesta gira en torno a la humanidad como eje central. Consideramos que los satélites espía deben estar hechos en pro de la humanidad, siempre teniendo presente que el espacio ultraterrestre es de la humanidad y, como tal, debe ser útil para protegerla.

Ahora bien, el origen de esta propuesta radica en que las sociedades modernas están siendo testigos de la aparición de nuevas amenazas globales tales como ataques cibernéticos, tráfico humano y terrorismo. Estas han crecido en importancia proporcionalmente con el aumento de los niveles de hiperconectividad e interdependencia de nuestra sociedad globalizada. Actores no gubernamentales, como organizaciones criminales transnacionales, son materias cruciales a considerar hoy en día en pos de ve- lar y mantener incólume, no solo la seguridad nacional, sino también la seguridad global.

Los Estados, al observar estas nuevas amenazas, propenden por salvaguardar la seguridad de sus ciudadanos mediante una visión muy corta para nuestra apreciación. Por ejemplo, Estados Unidos

hace un llamado por una mayor cooperación internacional para asegurar la utilización responsable, pacífica y sostenible del espacio ultraterrestre por todos los actores que lo explotan. Dicha cooperación es particularmente relevante en los campos de la exploración del espacio, vigilancia espacial y observación de la Tierra. Por otra parte, sigue estando considerablemente influenciado por visiones nacional-centralizadas y militares del espacio [...] Los Estados Unidos obviamente continúa considerando al espacio un lugar crucial para sus necesidades nacionales vitales y para priorizar usos comerciales y militares del espacio sobre aplicaciones sociales. (Al-Rodhan, 2012, p. 108)

Si han de preocuparse solamente por la seguridad nacional, entonces o se está cumpliendo con el principio I del Tratado de 1967: “La exploración y utilización del espacio ultraterrestre, incluso la Luna y otros cuerpos celestes, deberán hacerse en provecho y en interés de todos los países, sea cual fuere su grado de desarrollo económico y científico, e incumben a toda la humanidad". Todos los Estados han alcanzado el desarrollo científico para explotar las ventajas que ofrece el espacio ultraterrestre. De hecho, muy pocos Estados lo han alcanzado, por lo que son unos cuantos privilegiados los que pueden 
valerse de los beneficios del espacio ultraterrestre para velar por sus ciudadanos.

Para hacer un uso equitativo del espacio ultraterrestre con respecto a seguridad, los satélites espía deberían ser herramientas de seguridad global. Al-Rodhan ha diseñado un plan de cooperación internacional en el espacio ultraterrestre que reúne la seguridad humana, ambiental, nacional, transnacional y transcultural.

Los satélites de inteligencia defenderían la seguridad humana y la nacional. La seguridad humana es definida como "ausencia de miedo y ausencia de persecución” (ONU, 1994). En cuanto a la seguridad nacional, de acuerdo con James Lewis, existen tres razones esenciales de por qué los actores gubernamentales están luchando por usar el espacio para consolidar su seguridad nacional:

(i) el prestigio político y la influencia internacional que las actividades espaciales traen consigo, (ii) las capacidades tecnológicas que los programas espaciales crean y refuerzan y (iii) la ventaja informacional que los recursos y servicios espaciales pueden traerle a las operaciones militares y de seguridad, y al plan estratégico para mantener la seguridad. (Al-Rodhan, 2012, pp. 93, 94)

El diseño de esta defensa se basaría en el principio de cooperación internacional. Solo unos cuantos Estados tienen la capacidad de construir satélites espía, por lo tanto, estos serían los líderes del plan de defensa. Antes que nada, es esencial que el Estado de registro le notifique al Secretario de las Naciones Unidas cada lanza- miento de este tipo de satélites que realice. De esta manera, toda la comunidad internacional sabrá cuántos satélites de inteligencia están en funcionamiento y se contribuirá con la transparencia que debe existir en esta materia. Con la red de satélites de reconocimiento y vigilancia que existiría en el espacio ultraterrestre, el Estado de registro le notificaría a los Estados observados la situación. Así, si se descubre una situación que afecte la seguridad de los ciudadanos del Estado observado, el Estado dueño del satélite tendría la obligación de avisarle al Estado observado dicha situación. De la otra cara de la moneda, los Estados que aún no tengan la capacidad necesaria para utilizar el espacio ultraterrestre por medio de sus propios recursos, tendrían la obligación de soportar parte de la inversión necesaria para mantener esta red de vigilancia mediante el pago de parte del costo de dicha red a un costo razonable conforme a su desarrollo económico.

El teniente coronel retirado de la Fuerza Aérea colombiana, Juan Diego Vargas Calderón, nos da un ejemplo de cooperación que se acerca a esta propuesta. Las Fuerzas Armadas Revolucionarias de Colombia (FARC), un grupo al margen de la ley, tomó Mitú durante varios meses a pesar del esfuerzo de las Fuerzas Armadas por recuperar el territorio en el año de 1998. Gracias a imágenes obtenidas por parte de satélites estadounidenses utilizados para la misión militar y aérea que este país realizaba en Colombia, se recibió información de los lugares donde estaban ubicados los combatientes de este grupo. Así, la Fuerza Aérea colombiana pudo localizarlos y erradicarlos del territorio mediante 
bombardeos. También se ha utilizado la ayuda satelital ofrecida por parte de la Fuerza Armada estadounidenses para otras misiones militares en Colombia en el marco de su conflicto armado interno, sin embargo, Estados Unidos tiene total libertad de decidir qué información da o no a Colombia y últimamente ha restringido su ayuda debido a implicaciones políticas que surgirían de dicha cooperación.

Otro ejemplo se materializa en la alianza entre Estados Unidos y el Reino Unido que existe desde lo ocurrido contra las Torres Gemelas el 11 de septiembre de 2001 para combatir el terrorismo. Dentro de este plan de cooperación entre estos dos países se encuentran las actividades de la Oficina Nacional de Reconocimiento de los Estados (NRO). Por medio de esta oficina, el Reino Unido tiene acceso a algunos de los satélites espía estadounidenses que ofrecen una cobertura mundial. Para ello, el Reino Unido invierte en el sistema a falta de un sistema propio de vigilancia. De ese modo el Reino Unido tiene algún acceso privilegiado a la información (Svendsen, 2010).

Véase cómo esta propuesta sigue de cerca los Principios Relativos a la Teleobservación de la Tierra. El Principio II ordena que las actividades de teleobservación se realicen en provecho de toda la humanidad, "sea cual fuere su grado de desarrollo económico, social o científico y tecnológico y teniendo especialmente en cuenta las necesidades de los países en desarrollo". Los satélites de inteligencia observarían la Tierra sin discriminación alguna en busca que todos los ciudadanos gocen de una debida seguridad, sin importar su nacionalidad. Lo anterior es recalcado por el Principio IV que recuerda que las actividades de teleobservación deben seguir el Principio I del Tratado de 1967 en cuanto dispone que "la exploración y utilización del espacio ultraterrestre deberán hacerse en provecho y en interés de todos los países, sea cual fuere su grado de desarrollo económico y científico". El Principio V establece la obligación de cumplir con el principio de cooperación internacional. Para tal fin, los "Estados darán a otros Estados oportunidades de participar en esas actividades. Esa participación se basará en cada caso en condiciones equitativas y mutuamente aceptables". En este caso la notificación a los Estados sobre la observación que se está realizando sobre sus territorios para salvaguardar su seguridad y su obligación de avisar cualquier situación que atente contra dicha seguridad sería expresión de este principio. El Principio IX obliga a los Estados de registro a informarle al Secretario General de las Naciones Unidas cada lanzamiento de un satélite de teleobservación. Este es, precisamente, el primer paso de este plan de defensa. Finalmente, el Principio XII dispone que el Estado objeto de teleobservación tendrá acceso a los datos sin discriminación y a un costo razonable. La obligación de los Estados que se beneficiarían de la función de los satélites de reconocimiento y vigilancia de pagar parte de lo que cuesta montar esta red de defensa como contraprestación al acceso que tienen cumpliría con este principio. ${ }^{7}$

\footnotetext{
$7 \quad$ No está de más aclarar que las empresas privadas también deberían ser sujetos activos de esta propuesta. Muchos son los actores privados que lanzan satélites de teleobservación de la Tierra. Por tanto, un papel proactivo de estos actores es esencial para el desarrollo de esta propuesta.
} 
Finalmente, este plan ayudaría a fomentar la confianza y las relaciones amistosas entre los Estados, precisamente una de las grandes falencias de los satélites espía descritas con anterioridad. Esto se demuestra en cuanto cumple con las medidas de fomento de la confianza en el espacio ultraterrestre que ha establecido la ONU:

a. Las actividades que [...] promueven los usos pacíficos en favor de toda la humanidad [...] incluyen intercambios de información y personal, así como datos sobre el nivel y características de las fuerzas.

b. Las actividades que se permiten comprenden toda la gama de actividades que no están explícitamente prohibidas, aunque tampoco se alientan específicamente. Estas actividades incluyen medidas que reducen la aprensión que pueden tener los Estados en cuanto al potencial combativo para fines de actividades militares concretas. [...] notificar los movimientos militares y actividades conexas. (ONU, 1994, p. 33 , resaltado fuera del texto)

Así, los Estados estarían tras la seguridad global, no tras una visión a corto plazo y egoísta, contentándose tan solo con una seguridad local.

\section{CONCLUSIONES}

El Acuerdo Sobre las Actividades que Deben Regir las Actividades en la Luna y otros Cuerpos Celestes y el Tratado de 1967, establecen que el principio de uso pacífico excluye tanto los actos agresivos como los usos militares de carácter no agresivo que se le den al espacio ultraterrestre.
La regulación del derecho internacional y del derecho del espacio ultraterrestre frente al espionaje y a la militarización del espacio respectivamente da a entender que el uso de satélites espía está prohibido y la única excepción es el derecho a la legítima defensa instituido en el artículo 51 de la Carta de las Naciones Unidas.

La utilización de satélites espía en tiempos de paz viola el principio de cooperación internacional del Tratado de 1967, que también está contenido en los Principios V y XIII de los Principios Relativos a la Teleobservación de la Tierra.

El principio de no apropiación es la expresión que consolida el deseo de la comunidad internacional de utilizar el espacio ultraterrestre con fines pacíficos, en tanto le pertenece a toda la humanidad y no hay manera de que un Estado proclame soberanía sobre algún cuerpo celeste o parte del espacio. Sin embargo, el concepto de soberanía cambia en el ámbito terrestre y este es el que permite a los Estados, que en nombre de la legítima defensa de tal soberanía, se utilicen satélites espía.

Los satélites espía deben ser herramientas de seguridad global para hacer un uso equitativo del espacio ultraterrestre. Estos satélites deben ser utilizados bajo un plan de cooperación internacional en el espacio ultraterrestre que reúna la seguridad humana, ambiental, nacional, transnacional y transcultural. Este plan ha de basarse en el principio de cooperación internacional, siendo los Estados con capacidad de construir satélites espía los líderes del plan de seguridad. Además, es primordial que el Estado 
de registro le notifique al Secretario de las $\mathrm{Na}$ ciones Unidas cada lanzamiento de este tipo de satélites para que toda la comunidad internacional se entere de cuántos satélites de inteligencia están en funcionamiento y así se contribuya con la transparencia que debe existir en esta materia.

Este tipo de satélites puede hacer de nuestro planeta un panóptico o un lugar más seguro. Todo depende de si los Estados sitúan a la humanidad en el centro de sus políticas o no. El espacio ultraterrestre es de todos sin distinción alguna, está en nosotros la decisión de apersonarnos de esta situación y utilizarlo de manera que provea nuestra supervivencia sin miedos, sin guerras, y con dignidad.

\section{Bibliografía}

\section{Doctrina}

Al-Rodhan, N. (2012). Mate-Geopolitics of Outer Space. An Analysis of Space Power, Security and Governance. Oxford: Palgrave Macmillan.

Botero, C. (1996). ¿Qué queda de la soberanía de los Estados? Revista Universitas, 91, 66199.

Camargo, D. (2003). Lógicas del poder y regulación de espacios. Bogotá: Universidad Nacional de Colombia.

Charleston, J. (2010). What We Officially Know: Fifteen Years of Satellite Declassification. Recuperado de http://www.nro.gov/news/articles/2010/2010-04.pdf
Demester, G. (1996). Espionage in International Law. Recuperado de https://www.copyright.com/ccc/basicSearch.do?\&operation=go\&s earchType $=0$ \&lastSearch=simple \&all=on\&titleOrStd No $=0196-2035$

Diago, P. (2013). Satélites de teleobservación de la Tierra. Bogotá: Uniandes.

Easton, I. (2014). China's Evolving Reconnaissance- Strike Capabilities Implications for the U.S.-Japan Alliance. Project 2049. Recuperado del http://www2.jiia.or.jp/pdf/fellow_report/140219_JIIAProject2049_Ian_Easton_ report.pdf

Ferrer, A. (1976) Derecho Espacial. Tratado de Teleobservación: La teleobservación de la Tierra por Medios de la Tecnología Espacial (capítulo VIII). En Derecho. Buenos Aires: Plus Ultra.

Franco, I. (2013). Consenso, confianza y cooperación en el derecho del espacio ultraterrestre. Bogotá: Uniandes.

Golovine, M. N. (1962). Conflict in Space. Londres: Englewoods Cliffs.

laninni, M. C. (2012). Los desechos espaciales y su tratamiento en el derecho del espacio ultraterrestre. Bogotá: Uniandes.

Lachs, M. (2010). The Law of Outer Space. An experience on Contemporary Law-Making. Boston: Leiden. 
Naciones Unidas. (1984). Maintaining Outer Space for Peaceful Uses. Tokio: The United Nations University.

Naciones Unidas. (2003). Outer Space and Global Security. A source of Conflicto r Cooperation? Génova: Unidir.

Pereira, J.C. (1997). Los orígenes de la Guerra Fría. Madrid: Arco/Libros, S.L.

Svendsen, A. (2010). Intelligence Cooperation and the War on Terror. Anglo-American Security Relations After 9/11. Nueva York: Routledge Taylor \&Francis Group. Recuperado de http://cryptome.org/2013/01/aaronswartz/US-UK-Spy-Coop-Post-911.pdf

\section{Legislación}

Agencia para la Energía Nuclear. Estatuto de la agencia para la energía nuclear. Recuperado de http://www.iaea.org/About/statute.html\#A1.2

Naciones Unidas (1974). Convenio Sobre el Registro de Objetos Lanzados al Espacio Ultraterrestre. Recuperado de http://derecho.uniandes.edu.co/images/stories/programas_academicos/Espacio_Ultraterrestre/convenio_objetos_lanzados.pdf

Naciones Unidas (1979). Acuerdo que debe Regir las Actividades de los Estados en la Luna y otros Cuerpos Celestes. Recuperado de http://derecho.uniandes.edu.co/images/ stories/programas_academicos/Espacio_UItraterrestre/acuerdo_luna_cuerpos_celestes.pdf
Naciones Unidas (1967). Tratado sobre los principios que deben regir las actividades de los Estados en la exploración y utilización del espacio ultraterrestre, incluso la Luna y otros cuerpos celestes. Recuperado de http://derecho.uniandes.edu.co/images/stories/programas_ academicos/Espacio_Ultraterrestre/tratado_utilizacion_espacio_ultraterrestre.pdf

Naciones Unidas (1986). Principios Relativos a la Teleobservación de la Tierra desde el Espacio. Recuperado de http://derecho.uniandes.edu.co/images/stories/programas_academicos/Espacio_Ultraterrestre/principios_ teleobservacion.pdf

Naciones Unidas (1948). Carta de las Naciones Unidas. Recuperado de http://www.un.org/es/ documents/charter/ Naciones Unidas, Asamblea General. Resolución 41/65 del 3 de diciembre de 1986.

Naciones Unidas (1974). Resolución 3314.. Recuperado de http://www.dipublico.com.ar/4071/ definicion-de-la-agresion-resolucion-3314-xxix-de-laasamblea-general-de-las-naciones-unidas/

Tratado de la Antártida (1961). Recuperado de http://www.mindef.gob.pe/informacion/documentos/tratado_antartico.pdf

\section{Reportes}

Centro de Estudios Humanistas (2010). Hiroshima y Nagasaki. Marcha Mundial por la Paz y la No Violencia. Buenos Aires. Recuperado de http://www.cehba.org/wpcontent/uploads/materiales/Hiroshima\%20Nagasaki.pdf 
Century of Flight. The Exploration of Space. Recuperado de http://www.century-of-flight.net/Aviation\%20history/space/Meteorological\%20Satellites. htm

International Business Times. (2013). National Reconaissance Office Launched Secret Spy Satellites. Recuperado de http://www.ibtimes. com/secret-spy-satellites-launched-national-reconnaissance-office-atlas-v-rocket-carries-classified $\% 20$

Peru21 (2012). Crearán red de satélites para prevenir desastres. Recuperado de http:// peru21.pe/2012/03/19/tecnologia/crearan-redsatelites-prevenir-desastres-2016445\%20

Science for a Changing World (2014). Recuperado de https://Ita.cr.usgs.gov/declass
The American Task Force on Palestine (2010). Israel Launches Ofek 9SpySatellite. 24/01/.Recuperado de http://www.americantaskforce.org/ daily_news_article/2010/06/24/1277352000_12

\section{Páginas web}

Cantó, A. (2009). La pizarra de Yuri: Satélites espías. Recuperado de http://lapizarradeyuri.blogspot.com/2009/12/satelites-espias.html

Cornejo, J. M. (2011). Comunidad ISM: Los satélites de alta resolución. Recuperado de http:// www.comunidadism.es/blogs/los-satelites-de-altaresolucion 